\title{
Health Service Utilization for Eating Disorders: Findings From a Community-Based Study
}

\author{
Jonathan M. Mond, $\mathrm{PhD}^{1 *}$ \\ Phillipa J. Hay, MD, $\mathrm{PhD}^{2}$ \\ Bryan Rodgers, PhD $^{3}$ \\ Cathy Owen, MD ${ }^{4}$
}

\author{
ABSTRACT \\ Background: Prior use of health services \\ was examined in a community sample \\ of women with bulimic-type eating dis- \\ orders.
}

Method: Participants $(n=159)$ completed a structured interview for the assessment of eating disorder psychopathology as well as questions concerning treatment-seeking and type of treatment received.

Results: Whereas a minority (40.3\%) of participants had received treatment for an eating problem, most had received treatment for a general mental health problem (74.2\%) and/or weight loss (72.8\%), and all had used one or more self-help treatments. Where treatment was received for an eating or general mental health problem, this was from a primary care practitioner in the vast majority of cases. Only half of those partici- pants who reported marked impairment associated with an eating problem had ever received treatment for such a problem and less than one in five had received such treatment from a mental health professional.

Conclusion: Women with bulimic-type eating disorders rarely receive treatment for an eating problem, but frequently receive treatment for a general mental health problem and/or for weight loss. The findings underscore the importance of programs designed to improve the detection and management of eating disorders in primary care. (C) 2007 by Wiley Periodicals, Inc.

Keywords: health services; eating disorders; bulimia nervosa; binge eating disorder; mental health literacy

(Int J Eat Disord 2007; 40:399-408)

\section{Introduction}

Evidence suggests that few individuals affected by bulimia nervosa $(\mathrm{BN})$ and variants of $\mathrm{BN}$ not meeting formal diagnostic criteria receive treatment for an eating problem. In a community-based study of outcome in BN, Fairburn, and colleagues ${ }^{1}$ found

\footnotetext{
Accepted 30 January 2007

The Health and Well-Being Study was supported by The Canberra Hospital and by ACT Health and Community Care and by ACT Mental Health. Dr. Mond is supported by an NHMAC Public Health Fellowship.

Sections of this paper were presented at the International Academy of Eating Disorders Conference in Barcelona, June 7-10, 2006.

*Correspondence to: Dr. Jonathan M. Mond, School of Psychological Science, La Trobe University, Bundoore VIC 3083, Australia

E-mail: j.mond@latrobe.edu.au

${ }^{1}$ School of Psychological Science, La Trobe University, Bundoore VIC 3083, Australia

${ }^{2}$ Discipline of Psychiatry, School of Medicine, James Cook

University, Townsville, Australia

${ }^{3}$ National Centre for Epidemiology and Population Health,

Australian National University, Canberra, Australia

${ }^{4}$ Medical Education Unit, Medical School, Australian National

University, Canberra, Australia

Published online 11 May 2007 in Wiley InterScience

(www.interscience.wiley.com). DOI: 10.1002/eat.20382

(C) 2007 Wiley Periodicals, Inc.
}

that $26 \%$ of young adult women with a diagnosis of $\mathrm{BN}(n=102)$ had ever received treatment for an eating problem. In the New England Women's Health Project (NEWHP), an epidemiological study of BN and binge eating disorder (BED) among women aged $18-40$ years, $40.3 \%$ of BN cases $(n=62)$ had ever received treatment for an eating problem, notwithstanding the fact that most of these individuals had first met criteria for BN some 10 years earlier. ${ }^{2}$ In a sample of women aged 19-24 years recruited from a different region of the US, $22.4 \%$ of participants with a lifetime diagnosis of (primarily) BN or BED ( $n=76)$ ever had received treatment for an eating problem. ${ }^{3}$ These findings are concerning because specific psychotherapy focusing on eating disorder attitudes and behaviors is indicated in the treatment of BN and related disorders. ${ }^{4}$ In this study, BED is included among "bulimic-type" eating disorders, as in our earlier work. ${ }^{7,19}$ We recognize that this usage may not be universally accepted.

The use of evidence-based treatments appears to be particularly uncommon among women meeting criteria for BED and the nonpurging form of BN. In the NEWHP, ${ }^{2} 17.3 \%$ of women with a diagnosis of BED $(n=150)$ had ever received treatment for a problem with eating. Among participants $(n=14)$ 
meeting criteria for nonpurging $\mathrm{BN}, 21.4 \%$ had received treatment for a problem with eating. In contrast, $45.8 \%$ of individuals with a diagnosis of purging BN ( $n=48$ ) had received treatment for an eating problem. These findings may reflect higher levels of distress and functional impairment, and in turn a greater likelihood of referral, associated with the purging form of BN. ${ }^{5}$ However, they may also reflect the fact that individuals affected by BN-type disorders not involving the use of purging, and the primary care practitioners that they consult, may not readily recognize these disorders as being pathological. ${ }^{6,7}$

At the same time, evidence is accumulating to suggest that individuals with BN-type eating disorders often receive treatment for physical and mental health problems that cooccur with disordered eating, as well as for weight loss, and that nonspecific treatments of this kind, although unlikely to be of long-term benefit in reducing individuals' levels of eating disorder psychopathology, place a considerable burden on health services. A study of eating disorder patients $(n=78)$ referred to a specialist treatment facility in Scotland found that these patients had consulted a primary care practitioner significantly more often than a control group of individuals with no eating disorder during the 5 years prior to referral. ${ }^{8}$ The consultations encompassed a wide range of symptoms, including psychological, gastrointestinal, gynecological, and other nonspecific complaints. A study of women presenting to a family physician for routine gynecological examination found that patients who reported prior use of selfinduced vomiting, laxative misuse, or fasting ( $n=$ 17), made significantly more telephone calls to the managed care facility concerned, and received more referrals to specialist physicians than women with no history of eating-disordered behavior ${ }^{9}$ in the 12 months following the consultation.

In a small study of women with bulimic eating disorders ( $n=26$ ) in primary care, participants were more likely to seek help for a problem or perceived problem with excess weight $(61.5 \%)$ than for an eating problem (11.5\%), primarily from a lay organization such as Weight Watchers or from a primary care practitioner or alternative therapist. ${ }^{10}$ In a large-scale study of female primary care and obstetric-gynaecology patients, participants with $\mathrm{BN}$ or BED ( $n=289$ ) reported significantly more visits to a physician in the previous 3 months than those with no psychiatric disorder. ${ }^{11}$ This difference was no longer significant after comorbid anxiety and affective disorders were controlled, suggesting that elevated levels of health care utilization among individuals with BN and BED may be due to elevated levels of comorbid psychology, as opposed to eating disorder psychopathology per se. In the NEWHP, $29.2 \%$ of participants with purging $\mathrm{BN}$, $42.9 \%$ of participants with nonpurging BN, and $29.3 \%$ of participants with BED, had received treatment for a problem with weight. More recently, in a different sample, Striegel-Moore et al. ${ }^{12}$ found that both overall use of health services and use of outpatient psychotherapy were elevated among young adult women with a history of $\mathrm{BN}$ or $\mathrm{BED}$, and those with another psychiatric disorder, compared to a control group of healthy women.

As this review indicates, research addressing health service utilization for eating disorders has been sporadic. Further, whereas the evidence indicates that few individuals affected by $\mathrm{BN}$ and related disorders receive evidence-based treatment, little is known about the factors that predict treatment seeking and type of treatment sought. ${ }^{13}$ Eating disorders were not included in the two largescale epidemiological studies in which detailed information concerning use of health services for psychiatric disorders was obtained, namely, the United States National Comorbidity Study ${ }^{14}$ and the Australian National Survey of Mental Health and Well-Being. ${ }^{15}$ In these and other studies, impairment in psycho-social functioning was found to be the best predictor of whether professional treatment was received, ${ }^{16}$ although it was apparent that many individuals who experienced even severe disablement did not receive mental health care. ${ }^{17}$

The aim of the present study was to examine prior use of health services in a community sample of women with BN-type eating disorders recruited from a large-scale epidemiological study. We were particularly interested to consider the proportion of participants who had received treatment for an eating problem, the types of treatment received by individuals who had not received such treatment, and the variables associated with treatment-seeking and type of treatment received.

\section{Method}

\section{Study Design and Participants}

The research was conducted as part of the Health and Well-Being of Female ACT Residents Study, a two-phase epidemiological study of disability, health-service utilization, and "mental health literacy" associated with community cases of the more commonly occurring (BN-type) eating-disorders. ${ }^{6,7,18-20}$ Recruitment of participants at the first phase of the study has been detailed in a number of earlier publications. ${ }^{18-20}$ In brief, self-report questionnaires were completed by 5,255 female residents of the Australian Capital Territory (ACT) region of Australia, 
TABLE 1. Mean (SD) age, BMI, scores on measures of eating disorder psychopathology and functional impairment, and sociodemographic characteristics, for eating disorder cases ( $n=159)$ and "noncases" $(n=5,096)$

\begin{tabular}{lccrc}
\hline & $\begin{array}{c}\text { Cases } \\
\text { Mean (SD) }\end{array}$ & $\begin{array}{c}\text { Noncases } \\
\text { Mean (SD) }\end{array}$ & $t$ & $p$ \\
\hline Age (years) & $28.92(6.60)$ & $30.30(7.23)$ & 2.36 & $<.05$ \\
BMI (kg/m²) & $27.22(7.13)$ & $24.44(5.16)$ & -6.32 & $<.01$ \\
EDE-Q global score & $3.83(0.77)$ & $1.45(1.19)$ & -25.12 & $<.01$ \\
SF-12 MCS & (12.22) & $45.95(10.65)$ & 9.57 & $<.01$ \\
& $37.52(12.01$ & & $\chi^{2}$ & $p$ \\
Born in Australia & 90.6 & 85.1 & 3.66 & .06 \\
Married/living as married & 53.8 & 54.7 & 0.05 & .82 \\
English as first language & 95.0 & 91.7 & 2.22 & .14 \\
Employed full-time & 53.8 & 47.4 & 2.50 & .11 \\
Children (one or more) & 40.9 & 43.9 & 0.56 & .45 \\
Tertiary education & 32.1 & 38.1 & 2.35 & .13 \\
Private health insurance & 51.0 & 58.9 & 3.80 & .05 \\
\hline
\end{tabular}

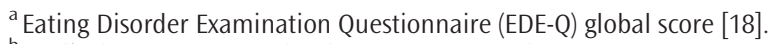

${ }^{b}$ Medical Outcomes Study Short Form Mental Component Summary scale [22]

aged 18-42 years. The questionnaire included measures of eating disorder psychopathology (EDE-Q), ${ }^{21}$ health-related quality of life (SF-12), ${ }^{22}$ height and weight, and sociodemographic information. Body mass index (BMI) $\left(\mathrm{kg} / \mathrm{m}^{2}\right)$ was calculated from self-reported height and weight. ${ }^{23}$ The sample comprised $\sim 10 \%$ of the total population of women aged 18-42 in the region and was representative of this population on a range of socio-demographic variables. ${ }^{18}$

Participants who met the screening criteria for a clinically significant eating disorder according to the EDE- $\mathrm{Q}^{23}$ were approached to participate in the second phase of the study, involving a face-to-face interview. The interview included a "mental health literacy" survey, ${ }^{24}$ diagnostic items of the eating disorder examination $(\mathrm{EDE})^{25}$ and questions addressing use of health services developed by the authors. Interviews were completed with 324 individuals, which represented a response rate of $76.6 \%$ at the second phase. Individuals interviewed were more likely to be married than those not interviewed (38.2\% vs. $29.8 \%$; $\chi^{2}=$ 9.58, $p<.05)$. There were no other differences between these sub-groups. The interval between receipt of the questionnaire and completion of the interview ranged from 4 days to 104 days, with a median of 28.0 days.

Participants in the present study were 159 individuals (48.8\% of the interviewed sample) who met the study criteria for a clinically significant eating disorder, on the basis of the EDE assessment. Mean age, BMI, scores on measures of eating disorder psychopathology and functional impairment, and sociodemographic characteristics, for study participants ("eating disorder cases"), and for the remainder of the total phase one sample ("noncases"), are given in Table 1.

\section{Assignment of Eating Disorder Diagnoses}

Eating disorder diagnoses as outlined in DSM-IV ${ }^{26}$ were assigned according to the operational criteria out- lined in the EDE manual. ${ }^{25}$ Hence, for the diagnoses of $\mathrm{BN}$ and BED, 12 or more episodes of binge eating over the past 3 months was required. In addition, cessation of menstruation was not required for the diagnosis of $\mathrm{AN}^{27}$ Participants who reported extreme weight or shape concerns and any regular eating disorder behavior and who did not meet criteria for AN or BN were assigned the diagnosis of eating disorder not otherwise specified (EDNOS) ${ }^{28}$ Current diagnoses were: BN: $n=30$ (purging: $n=9$, nonpurging: $n=21$ ), BED: $n=20$; and EDNOS (other than BED): $n=129$. The latter subgroup was comprised primarily of individuals of normal or above average weight who reported extreme weight or shape concerns and extreme weight-control behaviors, but did not report regular binge eating (objective bulimic) episodes. ${ }^{19}$

For the present study, the EDE was modified to assess both current and lifetime eating disorder behaviors and weight history. ${ }^{29}$ Lifetime diagnoses, assigned on the basis of this assessment, were: AN: $n=18$; BN: $n=51$; BED: $n=31$; and EDNOS (other than BED): $n=59$. Of the 51 participants with a lifetime diagnosis of $\mathrm{BN}, 25$ met criteria for BN purging sub-type whereas 26 met criteria for non-purging $\mathrm{BN}$. Of the 18 participants who had met criteria for AN, 14 had engaged in regular purging at some time and seven had met criteria for BN. Most (72.2\%) had missed one or more menstrual periods at the time other criteria for AN were met.

\section{Assessment of Health Service Utilization}

Participants were first asked about treatment or advice received specifically for a problem with eating, such as "eating too much in one go," "feeling out of control with your eating" or "being preoccupied with what or when you should eat." The person or persons from whom such advice or treatment had been received was noted and, for each provider mentioned, information concerning the participant's experience of the treatment was obtained. Similar sets of questions followed in which participants were asked about advice or treatment received for "other emotional problems, such as being anxious or depressed," and problems with weight, such as "wanting to lose (or gain) weight." Finally, participants were asked a series of "yes/no" questions concerning the use of various "lifestyle" interventions for any mental health problem, such as "getting information about the problem or available services," "getting out and about more/finding some new hobbies", "relaxation therapy or meditation" and "just talking about the problem."24a Questions con-

an the mental health literacy literature, interventions of this kind have sometimes been referred to as "self-help interventions". In the present study, the term "lifestyle interventions" is used in order to distinguish interventions of this kind from "self-help treatments" and/or or the use of a "self-help treatment manual" as these terms have been used in the eating disorder literature (e.g. Ref. 30). 
cerning the use of both nonprescription medicines (e.g., vitamins or minerals) and prescription (e.g., antidepressant or anxiolytic) medication were included in this section.

\section{Assessment of Functional Impairment}

Current functional impairment associated with general mental health was assessed using the mental component summary (MCS) Scale of the SF-12. ${ }^{22}$ A score of $\leq 30$ on this scale is considered to indicate severe impairment. ${ }^{31}$ In addition, questions concerning impairment in functioning associated with an eating problem were added to the EDE interview. Specifically, four questions assessed the extent to which functioning in each of four domains-main activity, home life, social life, and overall quality/enjoyment of life-was adversely affected by any problem with eating attitudes or behaviors. Participants who reported that functioning in at least one of the aforementioned domains was currently or ever affected "very much" or "extremely" were considered to have lifetime impairment relating to an eating problem.

\section{Statistical Analysis}

Data are reported as the percentage of participants reporting each type of treatment. Univariate associations between specific variables (e.g., eating disorder diagnosis, functional impairment) and use of health services were examined by means of $\chi^{2}$-tests. Separate logistic regression analyses with simultaneous variable entry were employed to identify the variables that best predicted (any) treatment for an eating problem and treatment for an eating problem from a mental health professional. Covariates in each analysis were: age; sociodemographic variables; (lifetime) obesity; (lifetime) eating disorder diagnosis; (lifetime) functional impairment associated with an eating problem; and current functional impairment as measured by the SF-12 MCS. Participants' first language was not included in the regression analyses on account of the small number of participants who did not have English as a first language. A significance level of 0.05 was adopted for all tests.

\section{Results}

Sixty-four participants (40.3\% of the total sample) had received advice or treatment specifically for a problem with eating. Of these, the vast majority $(85.9 \%)$ had received treatment from a general practitioner (GP) $(n=39)$, counselor $(n=23)$, or dietician ( $n=24)$. Eighteen participants $(11.3 \%)$ had received treatment from a psychologist ( $n=$ 15 ) and/or psychiatrist $(n=8)$. Seven participants had consulted an alternative therapist, whereas six individuals had participated in a self-help support group. Six participants $(3.8 \%)$ reported having received inpatient and/or partial hospitalization treatment specifically for a problem with eating.

One hundred and eighteen individuals $(74.2 \%$ of the total sample) had received treatment for a general mental health problem. Of these, $46.6 \%$ also had received treatment for an eating problem. Treatment for a general mental health problem was most commonly received from a GP $(n=75)$ or counselor ( $n=68$ ). Fifty-one individuals $(43.2 \%)$ had received such treatment from a psychologist ( $n$ $=42$ ) or psychiatrist $(n=22)$. Seventeen participants $(10.7 \%)$ had consulted an alternative therapist. Nine participants $(5.7 \%)$ reported having received inpatient and/or partial hospitalization treatment in relation to a general mental health problem.

One hundred and fifteen individuals $(72.8 \%$ of the total sample) had received treatment for a problem with weight, $40.0 \%$ of whom also had received treatment for an eating problem and $72.2 \%$ of whom also had received treatment for a general mental health problem. Of the 115 individuals who had received treatment for a weight problem, all but three had received this treatment for a perceived problem with overweight. Most had been overweight (BMI $\geq 25)$ ( $27.0 \%)$ or obese (BMI $\geq 30$ ) $(49.6 \%)$ at some time. Treatment for a weight problem was most often received from a commercial weight loss program $(n=70)$, GP $(n=54)$, or dietitian ( $n=39$ ).

Most participants ( $94.9 \%$ of the total sample) had received treatment for one of the three categories of problem (eating, general mental health, or weight) and all had used one or more lifestyle interventions, including: "talking to a friend" (85.4\%); "getting information about the problem or available services" (83.4\%); "getting out and about more/finding some new hobbies" (83.4\%); “joining a gym/getting a personal trainer" (73.9\%); and "taking vitamins or minerals" (65.0\%). Comparatively few participants reported having used antidepressant $(36.3 \%)$ or anxiolytic $(15.3 \%)$ medication (either $=40.8 \%$; both $=10.8 \%$ ) or a self-help treatment manual $(27.0 \%)$.

\section{Associations Between Eating Disorder Diagnosis and Use of Health Services}

The use of health services by lifetime eating disorder diagnosis is summarized in Table 2. Additional analysis indicated that the use of prescription medication and nonprescription medicines did not differ significantly as a function of diagno- 
TABLE 2. Health service utilization among community cases of eating disorders $(n=159)$ : treatment received by lifetime eating disorder diagnosis

\begin{tabular}{|c|c|c|c|c|c|c|}
\hline & \multicolumn{4}{|c|}{ Diagnosis } & & \\
\hline & AN $(n=18)$ & $\mathrm{BN}(n=51)$ & $\operatorname{BED}(n=31)$ & $\operatorname{EDNOS}(n=59)$ & & \\
\hline Any treatment & $\%$ & $\%$ & $\%$ & $\%$ & $\chi^{2}$ & $p$ \\
\hline Eating & 61.1 & 37.3 & 58.1 & 27.1 & 11.77 & .008 \\
\hline General mental health & 77.8 & 70.6 & 83.9 & 71.2 & 2.26 & .52 \\
\hline Weight & 50.0 & 70.6 & 87.1 & 74.1 & 8.10 & .04 \\
\hline Treatment by a mental health professional & $\%$ & $\%$ & $\%$ & $\%$ & $\chi^{2}$ & $p$ \\
\hline Eating & 22.2 & 13.7 & 12.9 & 5.1 & 4.79 & .19 \\
\hline General mental health & 22.2 & 33.3 & 38.7 & 30.5 & 1.53 & .68 \\
\hline Either & 38.9 & 35.3 & 45.2 & 30.5 & 1.98 & .58 \\
\hline
\end{tabular}

Notes: AN, anorexia nervosa; BN, bulimia nervosa; BED, binge eating disorder; EDNOS, eating disorder not otherwise specified.

TABLE 3. Health service utilization among community cases of eating disorders $(n=159)$ : treatment received by presence of functional impairment

\begin{tabular}{|c|c|c|c|c|c|c|c|c|}
\hline & \multicolumn{2}{|c|}{$\begin{array}{l}\text { Lifetime Impairment Associated } \\
\text { with an Eating Problem }{ }^{\mathrm{a}}\end{array}$} & & & \multicolumn{2}{|c|}{$\begin{array}{l}\text { Current Impairment in } \\
\text { General Mental Health }\end{array}$} & & \\
\hline & No $(n=67)$ & Yes $(n=92)$ & & & No $(n=108)$ & Yes $(n=44)$ & & \\
\hline Any treatment & $\%$ & $\%$ & $\chi^{2}$ & $p$ & $\%$ & $\%$ & $\chi^{2}$ & $p$ \\
\hline Eating & 26.9 & 50.0 & 8.63 & 0.003 & 34.3 & 52.3 & 4.25 & .04 \\
\hline General mental health & 65.7 & 80.4 & 4.42 & 0.04 & 65.7 & 90.9 & 10.05 & .002 \\
\hline Weight & 78.3 & 65.2 & 3.33 & 0.07 & 73.8 & 70.5 & 0.18 & .67 \\
\hline Treatment by a mental health professional & $\%$ & $\%$ & $\chi^{2}$ & $p$ & $\%$ & $\%$ & $\chi^{2}$ & $p$ \\
\hline Eating & 6.0 & 15.2 & 3.30 & 0.07 & 8.3 & 20.5 & 4.40 & .04 \\
\hline General mental health & 25.4 & 37.0 & 2.39 & 0.12 & 25.9 & 45.5 & 5.52 & .02 \\
\hline Either & 28.4 & 41.3 & 2.83 & 0.09 & 29.6 & 50.0 & 5.66 & .02 \\
\hline
\end{tabular}

${ }^{a}$ Marked impairment in one or more domains of functioning-main activity, home life, social life or overall quality of life-associated with an eating problem (see text).

${ }^{\mathrm{b}}$ Severe impairment in mental health as measured by the SF-12 (MCS $\left.\leq 30\right)[15]$.

sis (all $p>.05$ ). However, participants with a diagnosis of purging $\mathrm{BN}$ tended to be more likely to have used antidepressant medication than those with a diagnosis of nonpurging $\mathrm{BN}(44.0 \%$ vs $24.0 \% ; \chi^{2}=2.23, p=.14$ ).

\section{Associations Between Functional Impairment and Use of Health Services}

The use of health services by current and lifetime functional impairment is summarized in Table 3. Additional analysis indicated that, among those participants $(n=46)$ who reported (current or lifetime) functional impairment associated with an eating problem, but who had never received treatment for an eating problem, all but two (95.7\%) had received treatment for either a general mental health $(67.4 \%)$ or weight $(78.3 \%)$ problem.

Similarly, of the 21 individuals who reported current severe impairment as measured by the MCS, but who had never received treatment for an eating problem, all but one $(95.2 \%)$ had received treatment for a general mental health $(90.5 \%)$, or weight (76.2\%) problem. As can be seen in Table 3, treatment by a mental health professional for an eating problem was uncommon irrespective of the occurrence of functional impairment.

Participants who reported impairment associated with an eating problem were more likely to have used antidepressant $\left(44.0 \%\right.$ vs $25.8 \%, \chi^{2}=$ $5.48, p<.05)$ or anxiolytic $\left(24.2 \%\right.$ vs $3.0 \%, \chi^{2}=$ $13.21, p<.01)$ medication than those who did not. Participants who reported current impairment as measured by the MCS were more likely to have used antidepressant medication than those who did not $\left(51.2 \%\right.$ vs $30.8 \%$; $\left.\chi^{2}=5.46, p<.05\right)$.

\section{Multivariate Analysis}

Results of the logistic regression analyses are summarized in Table 4(a and b). When the analysis of variables associated with treatment for an eating problem (Table 4a) was repeated with sub-types of $\mathrm{BN}$ differentiated, both purging $\mathrm{BN}(B=-0.34$, SE $=0.64 ; \mathrm{OR}=0.71 ; 95 \% \mathrm{CI}=0.20,2.47 ; p=.59)$ and nonpurging $\mathrm{BN}(B=0.22, \mathrm{SE}=0.66$; $\mathrm{OR}=1.25$; $95 \% \mathrm{CI}=0.34,4.54 ; p=.74$ ) were nonsignificant. When the analysis of variables associated with treatment for an eating problem from a mental health specialist (Table $\mathbf{4 b}$ ) was repeated with subtypes of BN differentiated, the diagnosis of purging 
TABLE 4. Logistic regression analyses of the associations between study variables and treatment received ${ }^{a}$

\begin{tabular}{|c|c|c|}
\hline Predictor Variable & Odds Ratio $(95 \% \mathrm{Cl})$ & $p$ \\
\hline \multicolumn{3}{|l|}{ (a) Eating problem } \\
\hline Age & $0.992(0.905,1.088)$ & .866 \\
\hline History of obesity & $0.599(0.245,1.462)$ & .260 \\
\hline Born in Australia & $5.991(0.896,40.058)$ & .065 \\
\hline Married/living as married & $1.979(0.742,5.277)$ & .173 \\
\hline Employed full-time & $0.338(0.132,0.863)$ & .023 \\
\hline Children (one or more) & $0.564(0.159,2.002)$ & .376 \\
\hline Tertiary education & $1.891(0.717,4.991)$ & .198 \\
\hline Private health insurance & $1.177(0.511,2.715)$ & .701 \\
\hline Lifetime diagnosis of AN & $2.795(0.734,10.647)$ & .132 \\
\hline Lifetime diagnosis of $\mathrm{BN}$ & $1.071(0.388,2.955)$ & .895 \\
\hline Lifetime diagnosis of BED & $4.639(1.433,15.019)$ & .010 \\
\hline Current functional impairment & $2.677(1.094,6.556)$ & .031 \\
\hline Lifetime functional impairment & $3.476(1.402,8.616)$ & .007 \\
\hline Constant & 0.051 & .047 \\
\hline \multicolumn{3}{|c|}{ (b) Eating problem from a mental health specialist } \\
\hline Age & $1.103(0.960,1.267)$ & .168 \\
\hline History of obesity & $1.120(0.287,4.378)$ & .870 \\
\hline Born in Australia & $0.000(0.000,-)$ & .999 \\
\hline Married/living as married & $0.852(0.215,3.379)$ & .820 \\
\hline Employed full-time & $0.637(0.157,2.589)$ & .529 \\
\hline Children (one or more) & $0.324(0.046,2.275)$ & .257 \\
\hline Tertiary education & $1.773(0.411,7.652)$ & .443 \\
\hline Private health insurance & $2.261(0.611,8.358)$ & .221 \\
\hline Lifetime diagnosis of AN & $9.897(0.1205,81.272)$ & .033 \\
\hline Lifetime diagnosis of BN & $4.360(0.749,25.388)$ & .101 \\
\hline Lifetime diagnosis of BED & $4.054(0.602,27.281)$ & .150 \\
\hline Current functional impairment & $4.061(1.081,15.265)$ & .038 \\
\hline Lifetime functional impairment & $1.872(0.474,7.398)$ & .371 \\
\hline Constant & 0.000 & .998 \\
\hline
\end{tabular}

a Categorical covariates and treatment received were both coded 0 ('no') or 1 ('yes').

$\mathrm{BN}$ was significant $(B=2.29, \mathrm{SE}=1.03$; $\mathrm{OR}=9.88$; $95 \% \mathrm{CI}=1.32,74.11 ; p<.05)$, whereas the diagnosis of nonpurging $\mathrm{BN}$ was nonsignificant $(B=0.63$, $\mathrm{SE}=1.11 ; \mathrm{OR}=1.88 ; 95 \% \mathrm{CI}=0.21,16.47 ; p=.57)$.

\section{Conclusion}

We examined the use of health services in a community-based sample of women with eating disorders. Whereas a minority of participants had received treatment specifically for an eating problem, most had received treatment for a general mental health problem and weight loss, and all had used one or more "lifestyle" interventions. The use of nonprescription medicines, such as vitamins and minerals, also was common, whereas comparatively few participants had used antidepressant or anxiolytic medication. High levels of functional impairment and a lifetime diagnosis of BED were the variables most strongly associated with treatment for an eating problem. Participants born in Australia were also more likely to have received such treatment. High levels of functional impair- ment and a lifetime diagnosis of AN or BN purging subtype were the variables most strongly associated with treatment for an eating problem by a mental health professional. Where treatment had been received for an eating or general mental health problem, this was from a primary care practitioner in the vast majority of cases.

There were several notable strengths of the present research. First, participants were recruited from a large and representative community sample. Second, detailed information was obtained concerning both the nature of the problem for which treatment was received and the type of treatment received. Unlike previous studies, this assessment included both conventional sources of treatment and a range of other possible interventions. Third, assessment of both eating disorder psychopathology and health service utilization was carried out by trained interviewers. Finally, both current and lifetime eating disorder diagnoses were assessed, so that associations between participants' symptom histories and their use of health services could be considered.

Several limitations of the present study should also be acknowledged. First, there was no formal assessment of psychiatric disorders other than eating disorders. Hence, it was not possible to address the effects of comorbid diagnoses on health service utilization. Second, participants were required to classify the nature of the problem for which treatment was received into predetermined categories. Although this approach has been used in other epidemiological studies, ${ }^{2}$ the use of forced-choice options of this kind is inevitably associated with a loss of information. Third, results of the regression analysis relating to treatment for an eating problem from a mental health specialist need to be interpreted with caution given the small number of participants who received such treatment. Finally, the present findings should be interpreted in light of the fact that a comparatively low threshold for "eating disorder case" was employed. Nevertheless, this was a highly symptomatic group. The fact that only a small proportion of participants will have met formal diagnostic criteria for BN or BED is more likely a reflection of the overly restrictive nature of these criteria than of participants being "mild" cases. ${ }^{10}$

The present findings are consistent with those of other community- and primary care-based studies suggesting that the vast majority of individuals with $\mathrm{BN}$-type eating disorders do not receive treatment for an eating problem, but nevertheless receive treatment for comorbid psychiatric symptoms and for weight loss. ${ }^{1-3,8-12}$ In the present 
study, $40.3 \%$ of participants had received advice or treatment specifically for an eating problem, $74.2 \%$ had received advice or treatment for a general mental health problem, and $72.8 \%$ had received advice or treatment for weight loss. Where treatment was received for an eating or general mental health problem, this treatment was received from a primary care practitioner in the vast majority of cases. Treatment for weight loss was also typically obtained from, or in conjunction with, a primary care practitioner, namely, a general practitioner or dietitian. Hence, the present findings underscore the critical role of primary care practitioners in the treatment of eating disorders. ${ }^{32}$

Given that participants remained highly symptomatic, it is apparent that the nonspecific interventions they employed had little impact on their eating disorder psychopathology. Hence, an important implication of the present findings is that primary care practitioners may need to be educated as to the ineffectiveness of a treatment approach focusing on comorbid psychiatric problems among individuals affected by eating disorders. Health professionals working with individuals seeking treatment for weight loss also need to be alert to the symptoms of eating disorders among their clientele and to employ protocols that are effective in targeting both weight loss and disordered eating. Promising findings have been reported in recent studies designed to improve the detection and management of BN-type eating disorders in primary care (e.g. Ref. 33) and there is no reason that protocols of this kind could not be adapted for use in commercial weight-loss programs. However, more assertive outreach, in the form of eating disorders screening programs, may be needed to make the most of these developments. ${ }^{10}$

The present findings are also consistent with findings from epidemiological studies of the "more common" mental disorders, namely, anxiety, affective, and substance use disorders, in that the occurrence of impairment in everyday functioning was the best predictor of treatment-seeking behavior. ${ }^{16}$ This was the case for both impairment specific to disordered eating and impairment in general mental health as measured by the SF-12 MCS. However, and whereas the majority of participants with an eating disorder reported marked impairment in functioning associated with their eating behaviors, only half of those individuals who reported severe impairment had received treatment for an eating problem and less than one in five had received such treatment from a mental health professional. These findings, which also are consistent with findings from epidemiological studies of other mental disorders, ${ }^{17}$ are concerning and beg the question as to why specialist treatment for mental disorders is the exception, rather than the rule.

Jorm and colleagues, and others, have hypothesized that poor "mental health literacy" may be a major factor in accounting for low or inappropriate treatment seeking among individuals affected by mental disorders. ${ }^{34,35}$ Findings from several recent studies support this hypothesis. ${ }^{36-38}$ Aspects of mental health literacy relating to eating disorders that are likely to be important include: skepticism concerning the benefits of specialist treatment ${ }^{24}$; the perception that eating-disordered behavior may be normative or even desirable ${ }^{39}$; perceived stigma associated with disclosure of eating-disordered behavior ${ }^{40,41}$; the perception that one can, or should be able to, deal with such problems on one's $\mathrm{own}^{42}$; failure to recognize certain attitudes and behaviors as being symptomatic of an eating disorder $^{7}$; ego-syntonic aspects of eating-disordered behavior ${ }^{43,41}$; and the perception that comorbid mental health problems are "primary" and therefore to be given priority in treatment. ${ }^{44}$ It is important to note that these and other aspects of eating disorders mental health literacy may be evident not only among individuals affected, but among primary care practitioners and other treatment providers. ${ }^{32,45,46}$

Discrepancies between the beliefs and attitudes of individuals with eating disorders and those of treatment providers may also need to be addressed. For example, general practitioners are far more likely than members of the public to support the use of psychiatrists, and of antidepressant medication, and far less likely to support the use of "lifestyle" interventions, in the treatment of BN. ${ }^{45}$ Interventions designed to improve the detection and management of eating disorders in primary care may be of minimal benefit if individuals affected are sceptical of the benefits of "evidence-based" treatment. Hence, efforts to encourage the use of evidence-based treatments for $\mathrm{BN}$ and related disorders will need to be complemented by a more consumer-oriented approach, in which health professionals are encouraged to recognize individuals' belief systems and their potential effects on treatment-seeking and adherence to treatment. ${ }^{47,34}$

Of note is that a lifetime diagnosis of BED remained a significant predictor of treatment seeking for an eating problem, after obesity, functional impairment and other covariates were statistically controlled. This finding suggests that individuals with BED do recognize the need for treatment to focus on both disordered eating and weight loss. Consistent with this view, Brody and colleagues ${ }^{48}$ 
found, in a treatment-seeking sample of obese individuals with $\mathrm{BED}$, that most participants believed that their primary problem was an eating disorder. Further, participants who recognized an eating problem as being primary were more likely to prefer cognitive behavior therapy to behavioral weight loss than those who perceived over-weight to be their primary problem. Although the effects of specific psychotherapy on weight loss may be modest, ${ }^{4}$ the stabilization of eating behavior may be associated with improved quality of life among obese individuals who binge eat, irrespective of weight loss. ${ }^{49}$

The finding that the purging, but not the nonpurging form of BN was associated with treatment from a mental health specialist, in multivariate analysis, may reflect a tendency for individuals with eating disorders and primary care practitioners to be more likely to recognize, or to recognize as pathological, BN-type eating disorders characterized by the use of purging behaviors. ${ }^{2,7}$ If this is the case, then better information concerning nonpurging $\mathrm{BN}$ and $\mathrm{BED}$ needs to be made available to the public and to health professionals. In particular, it should be made clear that disorders of this kind may be no less severe than those involving purging in terms of their effects on psycho-social functioning. ${ }^{6,19}$ The finding that the diagnosis of BED, but not BN, was associated with treatment for an eating problem may reflect the ego-dystonic nature of binge eating in the absence of compensation. ${ }^{50}$ The observed association between a lifetime diagnosis of $\mathrm{AN}$ and treatment from a mental health professional probably reflects the fact that cases of AN are more conspicuous in primary care, hence more likely to be referred. ${ }^{51}$

Finally, it is notable that participants not born in Australia tended to be less likely to have received treatment for an eating problem than those born in Australia, after controlling for functional impairment and other potential covariates, since studies in the United States (US) have found that women from racial or ethnic minority populations are less likely than white women to receive treatment for an eating disorder. ${ }^{52-54}$ Reasons for differences in the utilization of health services for eating disorders between minority and majority populations may include differences in socioeconomic status and/or access to care, language barriers for immigrant populations, and the differing presentation of eating disorders among minority women. ${ }^{52-54}$ Since the ACT is a highly urbanized region, associations between sociodemographic variables and use of health services should be interpreted with caution. However, it may be noted that access to care is unlikely to have been a factor in the use of specialist treatment among participants in the present study, since a government-funded, outpatient treatment facility operated in the ACT for the duration of the study. ${ }^{55}$ The finding that participants who were employed full-time were less likely to have received treatment for an eating problem may reflect less time and/or motivation for the use of health services among individuals in this subgroup.

In conclusion, individuals with BN-type eating disorders rarely receive treatment for an eating problem, but frequently receive treatment for general mental health problems and for weight loss, typically from a primary care practitioner. A high level of functional impairment is the best predictor of treatment-seeking, although many individuals who experience even severe disablement do not receive mental health care. The findings underscore the important of programs designed to improve the detection and management of eating disorders in primary care.

The authors thank Ruth H. Striegel-Moore $\mathrm{PhD}$ and James E. Mitchell MD for helpful comments on an earlier version of this manuscript.

\section{References}

1. Fairburn CG, Cooper Z, Doll HA, Norman P, O'Connor M. The natural course of bulimia nervosa and binge eating disorder in young women. Arch Gen Psychiatry 2000;57:659-665.

2. Striegel-Moore RH, Cachelin FM, Dohm FA, Pike KM, Wilfley DE, Fairburn CG. Comparison of binge eating disorder and bulimia nervosa in a community sample. Int J Eat Disord 2001;29:157165.

3. Striegel-Moore RH, Dohm FA, Kraemer HC, Taylor C, Daniels S, Crawford PB, et al. Eating disorders in white and black women. Am J Psychiatry 2003;160:1326-1331.

4. Wilson GT, Shafran R. Eating disorders guidelines from NICE. Lancet 2005;365:79-81.

5. Garfinkel PE, Lin E, Goering P, Spegg C, Goldbloom DS, Kennedy S, et al. Purging and non-purging forms of bulimia nervosa in a community sample. Int J Eat Disord 1996;20:231-238.

6. Mond JM, Hay PJ, Rodgers B, Owen C, Mitchell JE. Purging and non-purging methods of weight control in a community sample of women. Aust N Z J Psychiatry 2006;40:136-142.

7. Mond JM, Hay PJ, Rodgers B, Owen C. Self-recognition of disordered eating among women with bulimic-type eating disorders: A community-based study. Int J Eat Disord 2006;39:747-753.

8. Ogg ED, Millar HR, Pusztai EE, Thom AS. General practice consultation patterns preceding diagnosis of eating disorders. Int J Eat Disord 1997;22:89-93.

9. Sansone RA, Wiederman MW, Sansone LA. Health-care utilization among with eating-disordered behavior. Am J Managed Care 1997;3:1721-1723. 
10. Hay PJ, Marley J, Lemar S. Covert eating disorders: The prevalence, characteristics and help-seeking of those with bulimic eating disorders in general practice. Prim Care Psychiatry 1998;4:95-99.

11. Johnson JG, Spitzer RL, Williams JBW. Health problems, impairment and illnesses associated with bulimia nervosa and binge eating disorder among primary care and obstetric gynaecology patients. Psychol Med 2001;31:1455-1466.

12. Striegel-Moore RH, Dohm FA, Kraemer HC, Schreiber GB, Crawford PB, Daniels SR. Health services use in women with a history of bulimia nervosa or binge eating disorder. Int J Eat Disord 2005;37:11-18.

13. Garvin V, Striegel-Moore RH. Health services research for eating disorders in the United States: A status report and a call to action. In: RH Striegel-Moore, L Smolak, editors. Eating Disorders: Innovative Directions in Research and Practice. Washington, DC: American Psychological Association, 2001, pp.135-52.

14. Kessler RC, Zhao S, Katz SJ, Kouzis AC, Frank RG, Edlund M, Leaf P. Past-year use of outpatient services for psychiatric problems in the National Comborbidity Survey. Am J Psychiatry 1999;156: 115-123.

15. Andrews G, Henderson S, Hall W. Prevalence, comorbidity, disability and service utilization. Overview of the Australian National Mental Health Survey. Br J Psychiatry 2001;178:145153.

16. Andrews G. Meeting the unmet need with disease management. In: Andrews G, Henderson S, editors. Unmet Need in Psychiatry. Cambridge: Cambridge University Press, 2000, pp. 11-36.

17. Andrews G, Slade T, Issakidis C. Deconstructing current comorbidity: data from the Australian National Survey of Mental Health and Well-Being. Br J Psychiatry 2002;181:306-314.

18. Mond JM, Hay PJ, Rodgers B, Owen C. Eating Disorder Examination Questionnaire (EDE-Q): Norms for young adult women. Behav Res Ther 2006;44:53-62.

19. Mond JM, Hay PJ, Rodgers B, Owen C, Crosby R, Mitchell JE. Use of extreme weight control behaviors with and without binge eating in a community sample of women: Implications for the classification of bulimic-type eating disorders. Int J Eat Disord 2006;39:294-302.

20. Mond JM, Hay PJ, Rodgers B, Owen C, Mitchell JE. Correlates of self-induced vomiting and laxative misuse in a community sample of women. J Nerv Ment Dis 2006;194:40-46.

21. Fairburn CG, Beglin SJ. Assessment of eating disorders: Interview or self-report questionnaire? Int J Eat Disord 1994;16: 363-370.

22. Ware JE, Kosinski M, Keller SD. A 12-item short-form health survey: Construction of scales and preliminary tests of reliability and validity. Med Care 1996;34:220-233.

23. Mond JM, Hay PJ, Rodgers B, Owen C, Beumont PJV. Validity of the Eating Disorder Examination Questionnaire (EDE-Q) in screening for eating disorders in community samples. Behav Res Ther 2004;42:551-567.

24. Mond JM, Hay PJ, Rodgers B, Owen C, Beumont PJV. Beliefs of the public concerning the helpfulness of interventions for bulimia nervosa. Int J Eat Disord 2004;36:62-68.

25. Fairburn CG, Cooper Z. The Eating Disorders Examination, 12th ed. In: Fairburn CG, Wilson GT, editors. Binge Eating: Nature, Assessment and Treatment. New York: Guilford Press, 1993, pp. 317-360.

26. American Psychiatric Association. Diagnostic and Statistical Manual of Mental Disorders, 4th ed (DSM-IV). Washington, DC: APA, 1994.

27. Watson TL, Anderson AE. A critical examination of the amenorrhoea and weight criteria for diagnosing anorexia nervosa. Acta Psychiatr Scand 2003;108:175-182.
28. Hay PJ, Fairburn CG, Doll H. The classification of bulimic eating disorders: A community-based cluster-analytic study. Psychol Med 1996;26:801-812.

29. Wade TD, Bergin JL, Tiggemann M, Bulik CM, Fairburn CG. Prevalence and long-term course of lifetime eating disorders in an adult Australian twin cohort. Aust N Z J Psychiatry 2006;40: 121-128.

30. Palmer RL, Birchall H, McGrain L, Sullivan V. Self-help for bulimic disorders: A randomized controlled trial comparing minimal guidance with face-to-face or telephone guidance. $\mathrm{Br}$ J Psychiatry 2002;181:230-235.

31. Sanderson K, Andrews G. Prevalence and severity of mental health-related disability and relationship to diagnosis. Psychiatr Serv 2002;53:80-86.

32. Currin L, Schmidt U, Waller G. Variables that influence diagnosis and treatment of the eating disorders within primary care settings: A vignette study. Int J Eat Disord 2007;40:257-262.

33. Banasiak SJ, Paxton SJ, Hay P. Guided self-help for bulimia nervosa in primary care: A randomized controlled trial. Psychol Med 2005;35:1283-1294.

34. Jorm AF, Angermeyer M, Katschnig H. Public knowledge of and attitudes to mental disorders: A limiting factor in the optimal use of treatment services. In: Andrews G, Henderson S, editors. Unmet Need in Psychiatry. Cambridge: Cambridge University Press, 2000:399-413.

35. Andrews G, Sanderson K, Slade T, Issakidis C. Why does the burden of disease persist? Relating the burden of anxiety and depression to effectiveness of treatment. Bull World Health Organ 2000;78:446-454.

36. Jorm AF, Medway J, Christensen H, Korten AE, Jacomb PA, Rodgers B. Public beliefs about the helpfulness of interventions for depression: Effects on actions taken when experiencing anxiety and depression symptoms. Aust N Z J Psychiatry 2000;34: 619-626.

37. Meltzer H, Bebbington P, Brugha T, Farrell M, Jenkins R, Lewis G. The reluctance to seek treatment for neurotic disorders. J Ment Health 2000;9:319-327.

38. Mojtabai R, Olfson M, Mechanic D. Perceived need and helpseeking in adults with mood, anxiety, or substance use disorders. Arch Gen Psychiatry 2003;59:77-84.

39. Mond JM, Hay PJ, Rodgers B, Owen C, Beumont PJV. Beliefs of women concerning the severity and prevalence of bulimia nervosa. Soc Psychiatry Psychiatr Epidemiol 2004;39:299-304.

40. Swan S, Andrews B. The relationship between shame, eating disorders and disclosure in treatment. Br J Clin Psychol 2003; 42:367-378.

41. Mond JM, Robertson-Smith G, Vitere A. Stigma and eating disorders: Is there evidence of negative attitudes towards individuals suffering from anorexia nervosa? J Ment Health 2006;15:519532.

42. Becker AE, Thomas JJ, Franko DL, Herzog DB. Disclosure patterns of eating and weight concerns to clinicians, educational professionals, family and peers. Int J Eat Disord 2005;38:18-23.

43. Serpell L, Treasure J. Bulimia nervosa: Friend or foe? The pros and cons of bulimia nervosa. Int J Eat Disord 2002;32:164170 .

44. Mond JM, Rodgers B, Hay PJ, Korten A, Owen C, Beumont PJV. Disability associated with community cases of commonly occurring eating disorders. Aust N Z J Public Heatlh 2004;28: 246-251.

45. Hay PJ, de Angelis C, Millar H, Mond JM. Eating disorder mental health literacy of general practitioners. Prim Community Care Psychiatry 2006;10:103-108.

46. Hay PJ, Darby A, Mond JM. Knowledge and Beliefs about Bulimia Nervosa and its Treatment: A comparative study of three disciplines. J Clin Psychol Med Settings 2007;14:59-68. 
47. Kessler RC. Psychiatric epidemiology: Selected recent advances and future directions. Bull World Health Organ 2000;78:464474.

48. Brody ML, Masheb RM, Grilo CM. Treatment preferences of patients with binge eating disorder. Int J Eat Disord 2005;37: 352-356.

49. Devlin MJ, Fischer SE. Treatment of binge eating disorder. In: Wonderlich S, Mitchell J, de Zwann M, Steiger H, editors. Eating Disorders Review: Part 1. Oxford: Radcliffe, 2005, pp. 27-41.

50. Hay PJ. Quality of life and bulimic eating disorder behaviors: Findings from a community-based sample. Int J Eat Disord 2003;33:434-442.

51. Turnbull S, Ward A, Treasure J, Jick H, Derby L. The demand for eating disorder care. An epidemiological study using the gen- eral practice research database. Br J Psychiatry 1996;169:705712.

52. Cachelin FM, Rebeck R, Veisel C, Striegel-Moore RH. Barriers to treatment for eating disorders among ethnically diverse women. Int J Eat Disord 2001;30:269-78.

53. Becker AE, Franko DL, Speck A, Herzog DB. Ethnicity and differential access to care for eating disorder symptoms. Int J Eat Disord 2003;33:205-212.

54. Cachelin FM, Striegel-Moore RH. Help seeking and barriers to treatment in a community sample of Mexican American and European American women with eating disorders. Int J Eat Disord 2006;39:154-61.

55. Mond JM, Hay PJ, Rodgers B, Owen C, Beumont PJV. Assessing quality of life in eating disorder patients. Qual Life Res 2005; 14:171-178. 